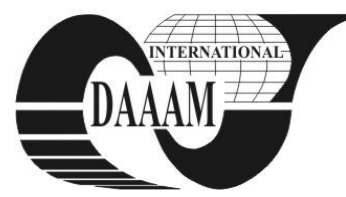

\title{
INFLUENCE OF THE SURFACE QUALITY ON THE STRESS STATE DURING ROTARY BENDING TEST
}

\author{
MALINA, J[iri]; MASEK, B[ohuslav] \& BEHULOVA, M[aria]
}

\begin{abstract}
Residual stresses arising from the production process can significantly affect the final stress state in individual components and thus also influence their lifetime. An alternative method of determination of final stresses by application of FEM simulation is presented in this paper. Three simulation models of the test specimen during the rotation bending fatigue test are presented. As the roughness of the surface also plays an important role, each model possesses a different combination of surface state and residual stresses. The stress fields in the specimen with real surface roughness and with integrated values of residual stresses experimentally measured using the $X$-ray diffraction are compared with the stress field in a specimen with ideally smooth surface.
\end{abstract}

Key words: numerical simulation, residual stresses, surface layer, surface roughness

\section{INTRODUCTION}

The products lifetime is one of the important parameters, which influence its usability in the practice. One of the possibilities how to determine the product lifetime is with rotation bending test. This fatigue test is commonly used for testing of the parts loaded by bending during rotation. As an example can be mentioned cars shaft, shaft of the wind-power plant, the motor rotating parts etc.

\section{EXPERIMENT}

The experimental part of this work was focused on the possibility of FEM simulation usage for the estimation of main stress parameters (specimen shape and roughness, residual stresses and way of loading) on the final stress state.

For the final stress state analyses the same loading parameters were used as during rotation bending test (Fig.1) DIN 50113 (1982). The loading frequency was $60 \mathrm{~Hz}$. The samples geometry was: diameter $3 \mathrm{~mm}$ and the length of the active part $12 \mathrm{~mm}$. (Fig. 2).

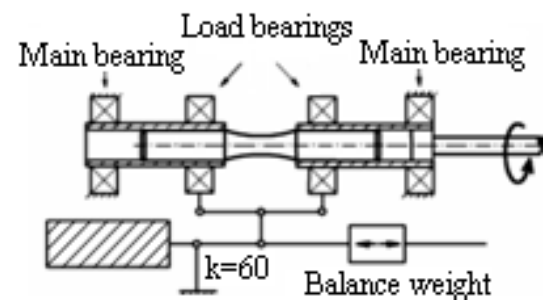

Fig. 1. The loading scheme at the rotary bending test

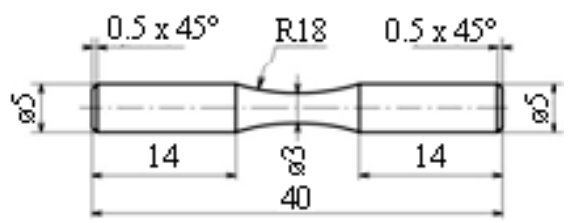

Fig. 2. The shape and the size of the specimen

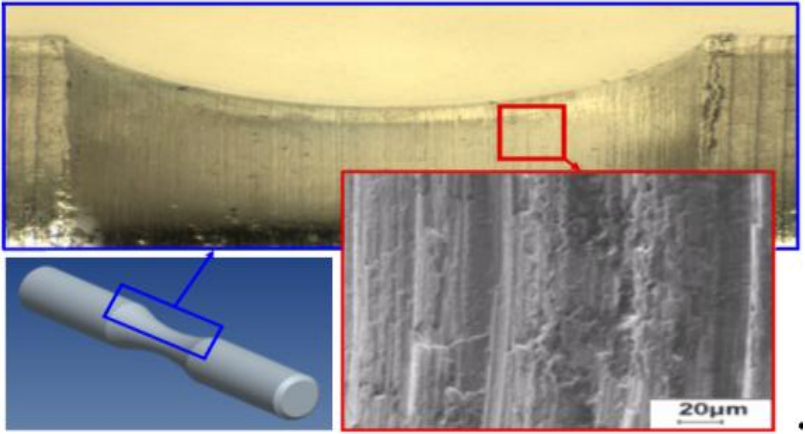

Fig. 3. The relief of the specimen's surface

The rise of the surface roughness (Fig. 3) during cutting creates places with the higher stress level and therefore the roughness of the final surface was measured.

Together with the surface relief the size and the character of the residual stresses have an important role. The pressure stresses lead during the fatigue loading to the fatigue live elongation, while the tension stresses have an opposite effect. The superposition of all stress factors leads to very complicated stress state which is difficult to measure.

The aim of this work was focused on the utilization of FEM simulation for investigation of the final stress state.

\subsection{The input date for the FEM simulation}

\subsubsection{The surface roughness measurement}

On the real test sample (from the steel 20MoCrS4) the roughness of the surface after the fine turning was measured (Fig. 4) in a contact way (Malina et al., 2006). The captured data were transformed to the model to represent the surface relief. After the testing of different technique of points fitting, the spline method has been chosen for the final use *** (2010). Ошибка! Источник ссылки не найден. This method suitably recorded the trend of microroughness of surface in the cross section which is perpendicular to the direction of cutting motion during turning.

\subsubsection{The residual stresses assignation}

For estimation of the size of residual stresses in the surface area X-ray diffraction analysis was used (Domankova et al., 2007), **** (2011).

The X-ray measurement was always repeated three times in each measured layer. The used value of the residual stress was the average of these three measurements.

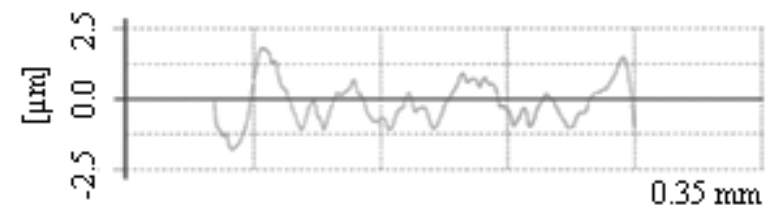

Fig. 4. Measured surface relief of a test sample 


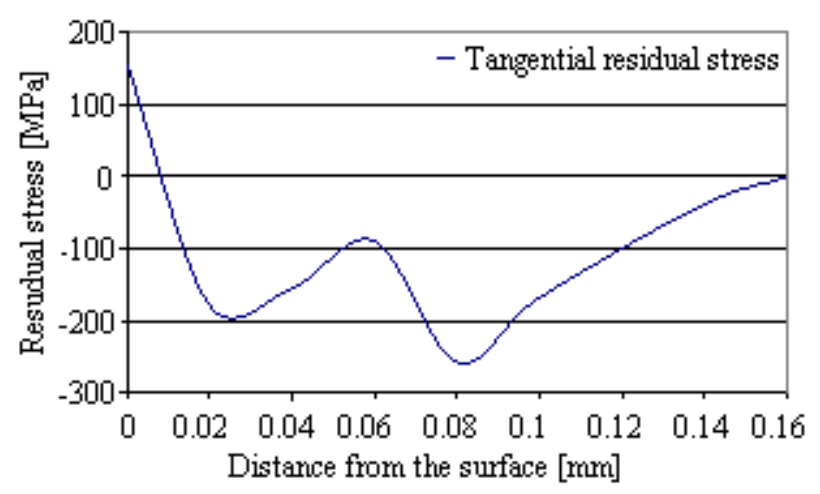

Fig. 5. The established residual stresses on the specimen

At the first, the value of the residual stress in the surface layer was measured. Then the surface layer was etched off with $0.02 \mathrm{~mm}$ step. This technique was made into the depth $0.16 \mathrm{~mm}$ where the value of the residual stress was $0.5 \mathrm{MPa}$.

The etching was used as a method avoiding the rise of any new stresses during the removal of surface layer (Malina et al., 2007). The measured local inhomogeneity of the residual stress in the depth $0.06 \mathrm{~mm}$ a $0.08 \mathrm{~mm}$ under the surface (Fig. 5) was used too in the FEM model.

\subsection{The FEM simulation model}

In the experiment the three FEM simulation models were simulated.

The first simulation model was with the ideal smooth surface without residual stresses. This model was used for determination of the basic theoretical stress originated only as the effect of the loading forces without other influences.

The second model was with the ideal smooth surface extended with the residual stresses established with the X-ray diffraction.

In the third model were included all the mentioned effects $i$. e. residual stresses and the surface roughness.

The models were designed like $2 \mathrm{D}$ and axisymmetric. The optimization of the size of the mesh element was made to provide sufficient accuracy of the calculation of influence of the surface relief. In the surface layer were the elements with the length of $0.002 \mathrm{~mm}$. The size of the elements was growing with growing distance from the surface. In the depth of 0.06 $\mathrm{mm}$ under the surface reached the element size $0.01 \mathrm{~mm}$. The remaining volume was meshed with the same element size.

The algorithm for generating thermally induced stress field was used for the achievement of required values of residual stresses. The temperature, which induced residual stress measured by X-ray diffraction, was established for each distance from surface.

This method induced in the sample required stress field and enables simulation of the stress state corresponding to the real state.

\section{RESULTS}

The FEM simulation results were achieved by the same simulation conditions such as loading, meshing etc. The results revealed that the maximal value of stress (about $49 \mathrm{MPa}$ ) occurs in the middle of the specimen with ideal smooth surface under the same loading. In the case of the model with real surface relief is the stress value in the middle of the specimen in the interval from $30 \mathrm{MPa}$ in local minimum to $67 \mathrm{MPa}$ in local maximum. The increase of the specimen load did not lead to expansion of this difference. The influence of the surface on the final stress state was obtained to the depth cca $0.02 \mathrm{~mm}$ (Fig.6).

The effect of residual stress was additive to the other stresses.

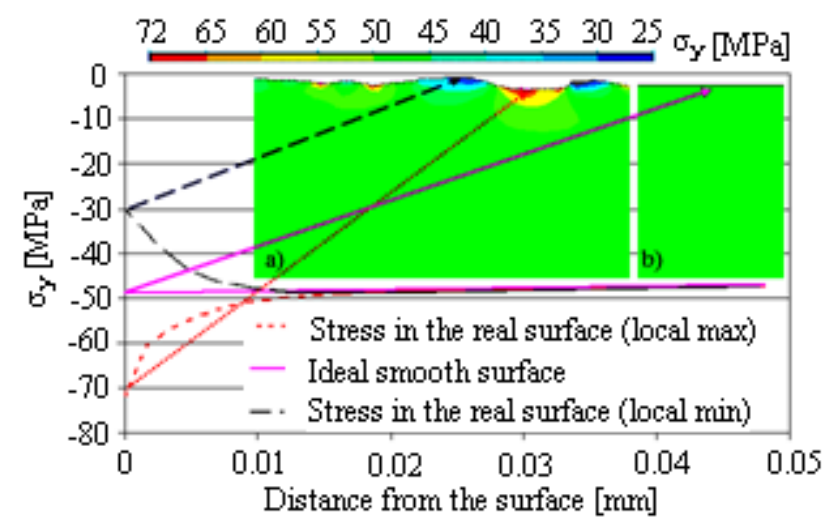

Fig. 6. The stress distribution on dependence from the distance from the surface

\section{CONCLUSION}

The concrete example confirmed that it is possible to make the FEM simulation model including all important effects influencing the final product lifetime.

In the performed simulation were except of the stresses initiated during the part loading reflected also the size of residual stresses and the surface roughness.

The difference between stress state on the ideal smooth specimen and on the specimen with the real surface with relief is apparent from the results of the FEM simulation. Thanks to this relief rise in the micro-volume of the surface layer local stress maxima and minima were observed with difference of about $40 \%$ in comparison with the ideal smooth surface

These results have shown another possible use of FEM simulation.

\section{ACKNOWLEDGEMENTS}

This paper includes results created within the project 1M06032 Research Centre of Forming Technology. The project is subsidised from specific resources of the state budget for research and development.

\section{REFERENCES}

DIN 50113 Norm (1982)

Malina, J., Behulova, M., Stankova, H., Masek, B., (2006) FEM analysis of the influence of surface roughness on the stress distribution during rotation-bending test, Zivotnost materialu a konstrukci, Brno, Czech Republic, ISBN 80239-6751-7, pp. 105-109

*** Ansys Theoretical Manual, Release 10.0. (2005). Available from:

http://www.tsne.co.kr/intra/data_center/ansys/theory.pdf Accessed on: 2010-02-20

Domankova, M., Caplovic, L., Janovec, J. Experimentálne metody studia materialov I, (2007), pp 219 ISBN 978-80227-2741-9, STU v Bratislave, Bratislava,

**** (2011) Czech Technical University in Prague Faculty of Nuclear Sciences and Physical Engineering Department of Physical Electronics http://vega.fjfi.cvut.cz/docs/sfbe/rtg_difrakce/4.html Accessed on: 2011-06-01

Malina, J., Behulova, M., Stankova, H., Masek, B., (2007) Analyse des Einflusses der Eigenspannung und des Oberflächenreliefs auf die Spannungsverteilung unter Anwendung von FEM Simulation, XXVI. Verformungskundliches Kolloquium, ISBN 978-3-90207809-4, pp 181-188, Harrer O., Montanuniversität Leoben, Planneralm 